\title{
Development of the Euro fracture toughness dataset
}

First published in:

Engineering Fracture Mechanics 69 (2002), pp. 421-449

(c) 2002 Elsevier Science Ltd All rights reserved.

- Reprint -

Authors:

J. Heerens

D. Hellmann 